\title{
TIMED BARIUM ESOPHAGOGRAM: A SIMPLE PHYSIOLOGIC ASSESSMENT FOR ACHALASIA
}

Srdjan V. Kostic, MD

Thomas W. Rice, MD ${ }^{\mathrm{a}}$

Mark E. Baker, MD $^{\mathrm{b}}$

Malcolm M. DeCamp, MD

Sudish C. Murthy, MD, $\mathrm{PhD}^{\mathrm{a}}$

Lisa A. Rybicki, MS

Eugene H. Blackstone, MD ${ }^{\mathrm{a}, \mathrm{c}}$

Joel E. Richter, MD ${ }^{d}$
Objective: Success of achalasia therapy is difficult to determine because repeated physiologic study is impractical and symptoms are subjective. Timed barium esophagography directly measures esophageal emptying and is simple to perform. This study (1) evaluates the assessment of myotomy by timed barium esophagography and (2) compares it with premyotomy and postmyotomy symptoms.

Methods: Fifty patients ingested $250 \mathrm{~mL}$ low-density barium and had upright films at 1,2, and 5 minutes premyotomy. Forty-five underwent repeat timed barium esophagography 8 weeks (median) postmyotomy. Premyotomy and postmyotomy height and width of the barium column were compared and related to symptoms.

Results: At 1, 2, and 5 minutes premyotomy, median barium column height was 19,17 , and $15 \mathrm{~cm}$, and width was $5.2,4.8$, and $4.5 \mathrm{~cm}$, respectively. Surgery reduced these to $7.0,5.0$, and $1.0 \mathrm{~cm}$ and to $3.5,3.0$, and $1.0 \mathrm{~cm}$, respectively $(P<.001)$. Postmyotomy complete esophageal emptying was seen in $29 \%, 36 \%$, and $49 \%$ at 1, 2, and 5 minutes. Postmyotomy height was unrelated $(r \sim 0.2)$ to premyotomy height but was directly related to premyotomy width $(r=0.3-0.5 ; P<.05)$; postmyotomy width was directly related to premyotomy width $(r \sim 0.6 ; P<.001)$. Premyotomy dysphagia was more severe when little change in width occurred from 1 to 5 minutes $(r=0.26, P=.07)$. Premyotomy regurgitation was more severe the higher the barium column $(r \sim 0.4, P<.007)$. Surgery relieved symptoms in the majority of patients (grade $2-5$ dysphagia from $72 \%$ to $4 \%$, grade 2-5 regurgitation from $79 \%$ to $4 \%$ ). Postmyotomy symptoms were unrelated to the timed barium esophagogram.

Conclusions: (1) The timed barium esophagogram gives objective confirmation of successful myotomy. (2) Symptoms are unreliable in assessing esophageal emptying. (J Thorac Cardiovasc Surg 2000;120:935-46)
From the Center for Swallowing and Esophageal Disorders, Departments of Thoracic and Cardiovascular Surgery, ${ }^{a}$ Radiology, ${ }^{\mathrm{b}}$ Biostatistics and Epidemiology, ${ }^{\mathrm{c}}$ and Gastroenterology, ${ }^{\mathrm{d}}$ The Cleveland Clinic Foundation, Cleveland, Ohio.

Read at the Eightieth Annual Meeting of The American Association for Thoracic Surgery, Toronto, Ontario, Canada, April 30-May 3, 2000.

Received for publication April 7, 2000; revisions requested June 20, 2000; revisions received July 18, 2000; accepted for publication July 26, 2000.

Address for reprints: Thomas W. Rice, MD, The Cleveland Clinic Foundation, 9500 Euclid Ave, Desk F25, Cleveland, OH 44195 (E-mail: ricet@ccf.org)

Copyright (c) 2000 by The American Association for Thoracic Surgery

$0022-5223 / 2000 \$ 12.00+0 \quad \mathbf{1 2 / 6 / 1 1 0 4 6 3}$

doi: $10.1067 / \mathrm{mtc} .2000 .110463$
A chalasia is an immune-mediated destruction of the A esophageal myenteric plexus whose etiology is unknown. ${ }^{1-4}$ Esophageal denervation markedly impairs esophageal emptying and its perception. ${ }^{5}$ Classic symptoms include dysphagia, regurgitation, chest pain, and, on occasion, heartburn. Traditionally, symptoms have been used for assessment of achalasia and the response to treatment. However, symptoms have been poor predictors of successful therapy in long-term follow-up. ${ }^{6}$

The goal of achalasia therapy is to improve esophageal emptying. This has been difficult to quantify. The timed barium esophagogram (TBE) directly measures esophageal emptying. It is easily performed, inexpensive, quantitative, repeatable, and comfortable 
Table I. Characteristics of patients, their achalasia, and its treatment $(n=52)$

\begin{tabular}{lcc}
\hline Characteristic & No. & $\%$ \\
\hline $\begin{array}{l}\text { Demography } \\
\quad \text { Men }\end{array}$ & 26 & 50 \\
Esophageal manometry & & \\
Lower esophageal relaxation & & \\
$\quad$ Abnormal & 52 & 100 \\
Mean body amplitude & & \\
$\quad>35$ (normal) & 13 & 30 \\
$\quad 33$ (abnormal) & 31 & 70 \\
$\quad$ Not measured & 8 & \\
Previous therapies (before TBE) & & \\
Botox injections & & \\
0 & 41 & 79 \\
1 & 5 & 10 \\
2 & 6 & 12 \\
Pneumatic dilations & & \\
0 & 21 & 40 \\
1 & 11 & 21 \\
2 & 16 & 31 \\
3 & 2 & 4 \\
5 & 1 & 2 \\
10 & 1 & 2 \\
Previous operation & 4 & 8 \\
Number of previous treatment modalities & & \\
None & 14 & 27 \\
1 & 30 & 58 \\
2 & 8 & 15 \\
\hline
\end{tabular}

TBE, Timed barium esophagogram.

for the patient. ${ }^{7,8}$ This study (1) evaluates TBE assessment of myotomy and (2) compares the TBE findings with symptoms.

\section{Patients and methods}

Patients. From March 1995 to April 1999, 52 patients underwent esophagomyotomy for achalasia. The diagnosis was based on esophageal manometric criteria (incomplete lower esophageal sphincter relaxation and aperistalsis). Preoperative evaluation included clinical symptom assessment and upper gastrointestinal endoscopy. A TBE was performed on 50 of these patients as a baseline study premyotomy and in 45 of the 52 patients approximately 8 weeks postmyotomy. Mean age was $48 \pm 17$ years; other patient characteristics are presented in Table I.

TBE. While standing, the patient ingested a low-density barium sulfate suspension (45\% weight in volume) (E-ZPAQUE; E-Z-EM, Westbury, NY). Patients were instructed to drink up to $250 \mathrm{~mL}$ within 30 to 45 seconds. The maximum volume was the amount the patient could tolerate comfortably without regurgitation or aspiration. In 29 of 50 patients, the amount of barium ingested was a full $250 \mathrm{~mL}$. With the patient in a slightly left posterior oblique position, three-onone spot films $(35 \times 35 \mathrm{~cm})$ of the esophagus were taken 1,2 , and 5 minutes after the last swallow of barium (Fig 1, A). In each patient, the same volume of barium was given for both the premyotomy and postmyotomy studies (Fig 1, B). The barium ingestion distance from the distal esophagus to the top of the barium column (barium height) and the maximum diameter of the barium column (barium width) were calculated. The 1-, 2-, and 5-minute barium heights and widths, as well as changes from 1 to 5 minutes, were used for analysis of the degree of esophageal emptying and reduction in esophageal diameter.

Symptom evaluation. Premyotomy and postmyotomy symptom evaluations were performed and recorded in the medical record according to a structured, graded format. ${ }^{8} \mathrm{We}$ extracted the evaluation mode closest to the time of the TBE. Symptoms assessed were dysphagia, regurgitation, chest pain, and heartburn. The frequency of each symptom was graded on a scale from 0 to $5(0=$ none; $1=$ rare, 1 per month or less; $2=$ occasional, once a week, up to 3 to 4 times a month; 3 = frequent, 2 to 4 times a week; $4=$ often, once a day; 5 = severe, several times a day).

Data analysis. Categorical data are summarized as frequencies and percentages. Continuous variables are summarized parametrically as mean and standard deviation or nonparametrically as box plots with median, 25th, and 75th percentiles (bottom and top of box), range, and individual points.

Initially, we attempted to model the time-related change in height, width, and the product of these to estimate the rate of esophageal emptying. However, the accommodation of the esophagus to barium precluded a consistent pattern. Therefore, each timed measurement and the difference between the 5minute and 1-minute values were analyzed for correlates of both barium height and width by multiple linear regression. Version 6.12 of SAS for Unix was used in the analyses (SAS Institute, Inc, Cary, NC). Regression diagnostics used were those recommended by Neter and colleagues. ${ }^{9}$ McNemar's test was used to determine whether symptom prevalence changed from the premyotomy to postmyotomy assessment.

The focus of the analysis of premyotomy TBE was its relation to premyotomy symptoms (presence and graded severity of dysphagia, regurgitation, chest pain, and heartburn). We also sought associations with patient demography (sex, age, weight), lower esophageal pressure and relaxation (millimeters of mercury), and previous therapies (botulinum toxin type A injections [Botox; Allergan, Inc, Irvine, Calif], pneumatic dilations, and lower esophagus operations).

The focus of the analysis of the postmyotomy TBE was (1) the relation to premyotomy values of height and width, (2) postmyotomy symptoms, and (3) preoperative symptoms, manometry, and therapies.

\section{Results}

\section{Success of myotomy}

Barium column height. In a person with normal esophageal function, the esophagus should be emptied of $250 \mathrm{~mL}$ of barium within 10 to 20 seconds and have no residual barium at 1 minute. In contrast, these patients with achalasia had a median premyotomy barium column height of 19,17 , and $15 \mathrm{~cm}$ at 1,2 , and 5 minutes after barium ingestion (Fig 2). Postmyotomy, 

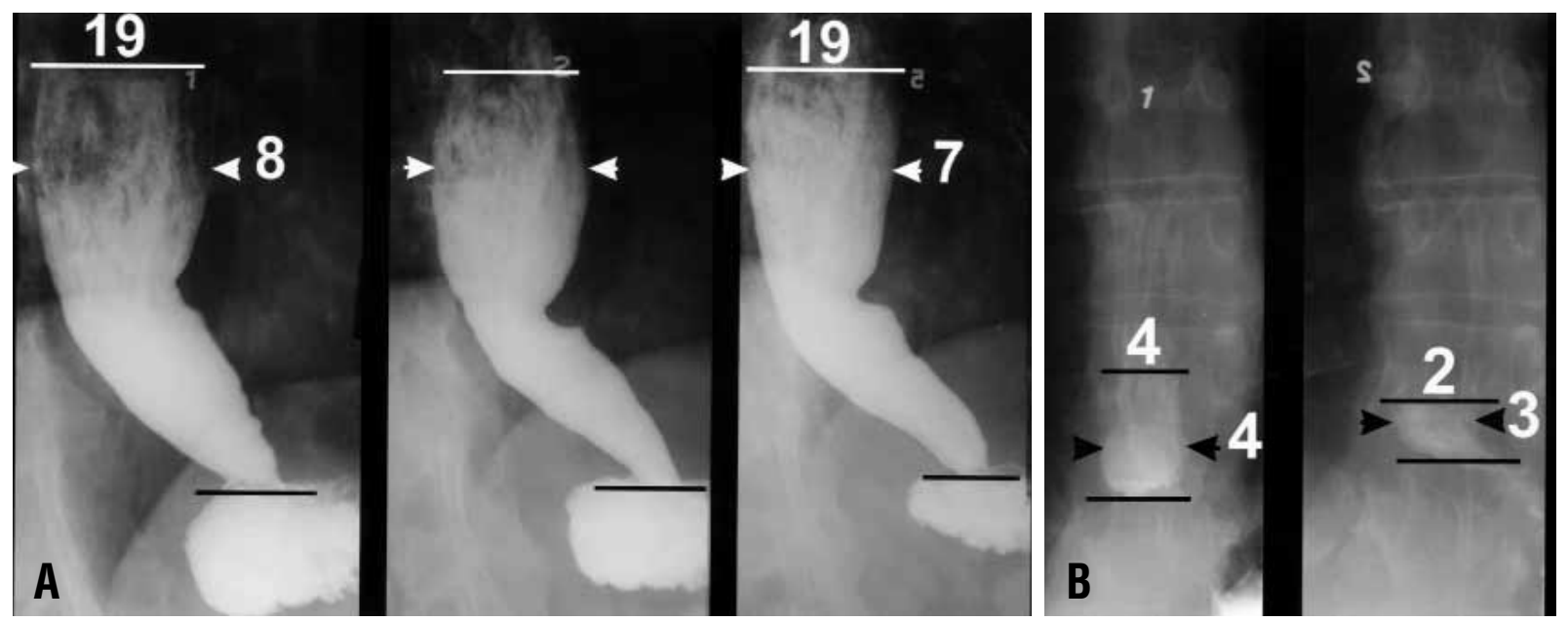

Fig 1. Esophagogram after ingestion of $250 \mathrm{~mL}$ of barium. Height of barium column is indicated by the transverse line and numeric values. Width of the barium column is indicated by arrows and numeric values. A, Premyotomy TBEs at 1, 2, and 5 minutes. B, Postmyotomy TBEs at 1 and 2 minutes. Complete esophageal emptying was observed at 5 minutes.

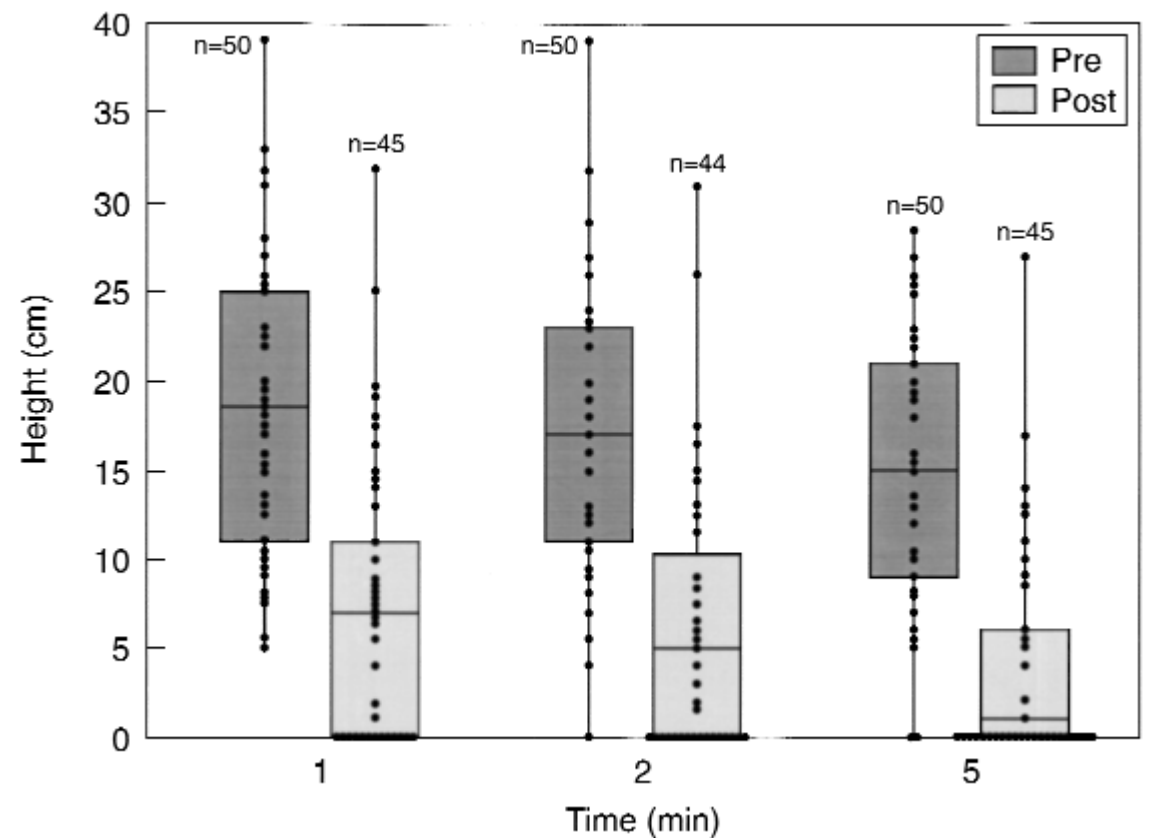

Fig 2. Premyotomy and postmyotomy barium column height at 1,2 , and 5 minutes. The depiction is a box-andwhiskers plot, enclosing the 25th to 75th percentiles of the data. The median is depicted by the horizontal line. Individual data points are shown by solid dots.

13 (29\%) patients had complete esophageal emptying of ingested barium (height $=0)$ by 1 minute, $16(36 \%)$ by 2 minutes, and 22 (49\%) by 5 minutes. Median postmyotomy barium column heights were 7.0, 5.0, and 1.0 $\mathrm{cm}$ at 1,2 , and 5 minutes after barium ingestion (Fig 2, $P<.001$ at each time).
The relation of premyotomy and postmyotomy barium column heights at 1 minute for each patient is depicted in Fig 3. Regardless of the premyotomy height, some patients had complete emptying by 1 minute postmyotomy. Thus, correlation between the premyotomy and postmyotomy barium column heights 


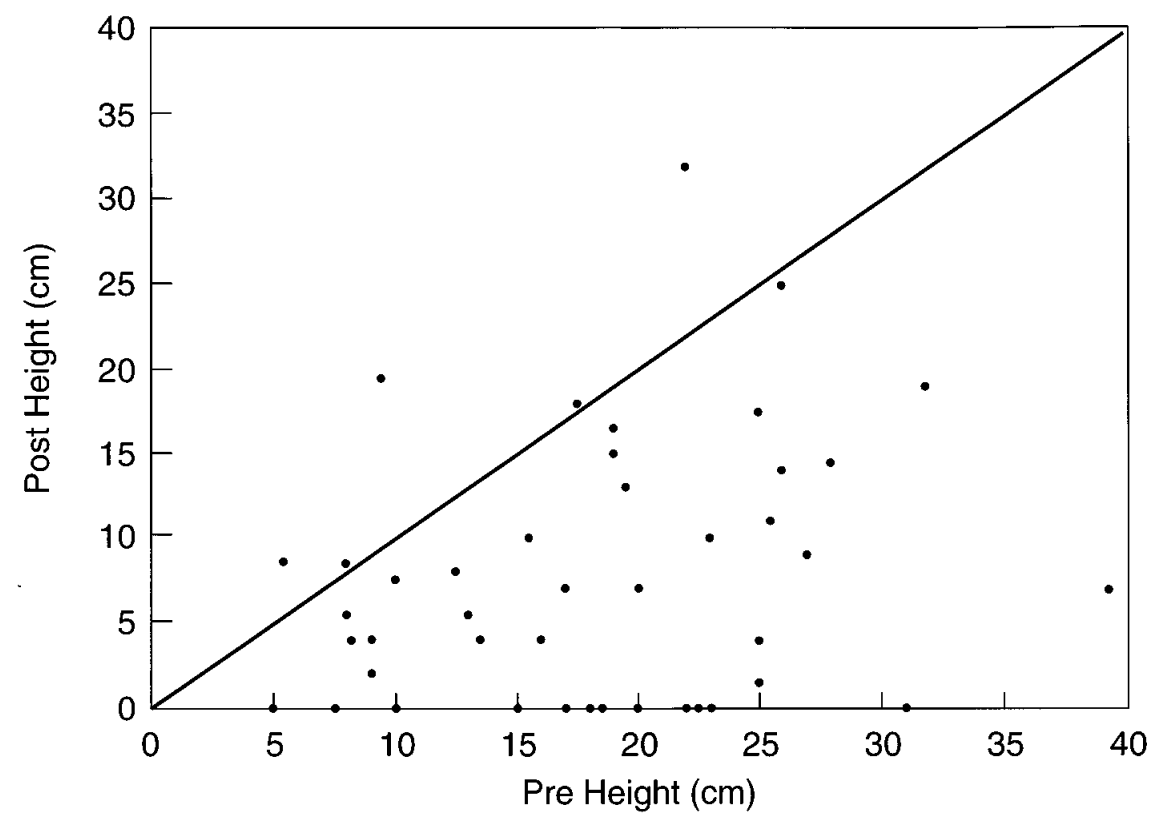

Fig 3. Relation of postmyotomy barium column height at 1 minute to premyotomy height at 1 minute. The line of identity is shown.

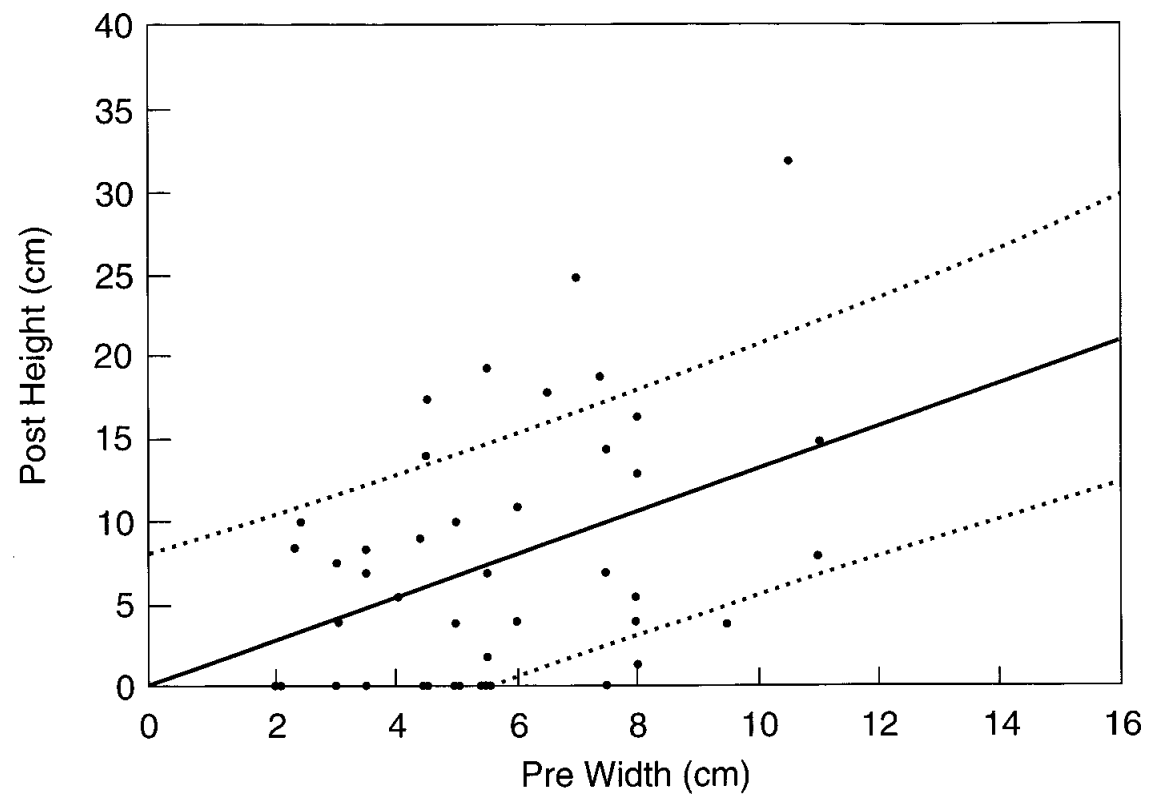

Fig 4. Relation of postmyotomy barium column height at 1 minute to premyotomy width at 1 minute. The line of regression is shown enclosed within dotted confidence intervals equivalent to 1 standard deviation.

was poor $(r=0.26, P=.09, \mathrm{n}=43$ at 1 minute; $r=0.19$, $P=.2, \mathrm{n}=42$ at 2 minutes; and $r=0.18, P=.2, \mathrm{n}=43$ at 5 minutes). In contrast, the postmyotomy height strongly and directly correlated with premyotomy barium column width $(r=0.32, P=.04, \mathrm{n}=43$ at 1 minute; $r=0.36, P=.02, \mathrm{n}=42$ at 2 minutes; and $r=$ $0.50, P<.001, \mathrm{n}=43$ at 5 minutes) (Figs 4 and 5).

Demography, esophageal manometry, and prior therapy correlated weakly with premyotomy or postmyotomy barium column height except that the larger the 

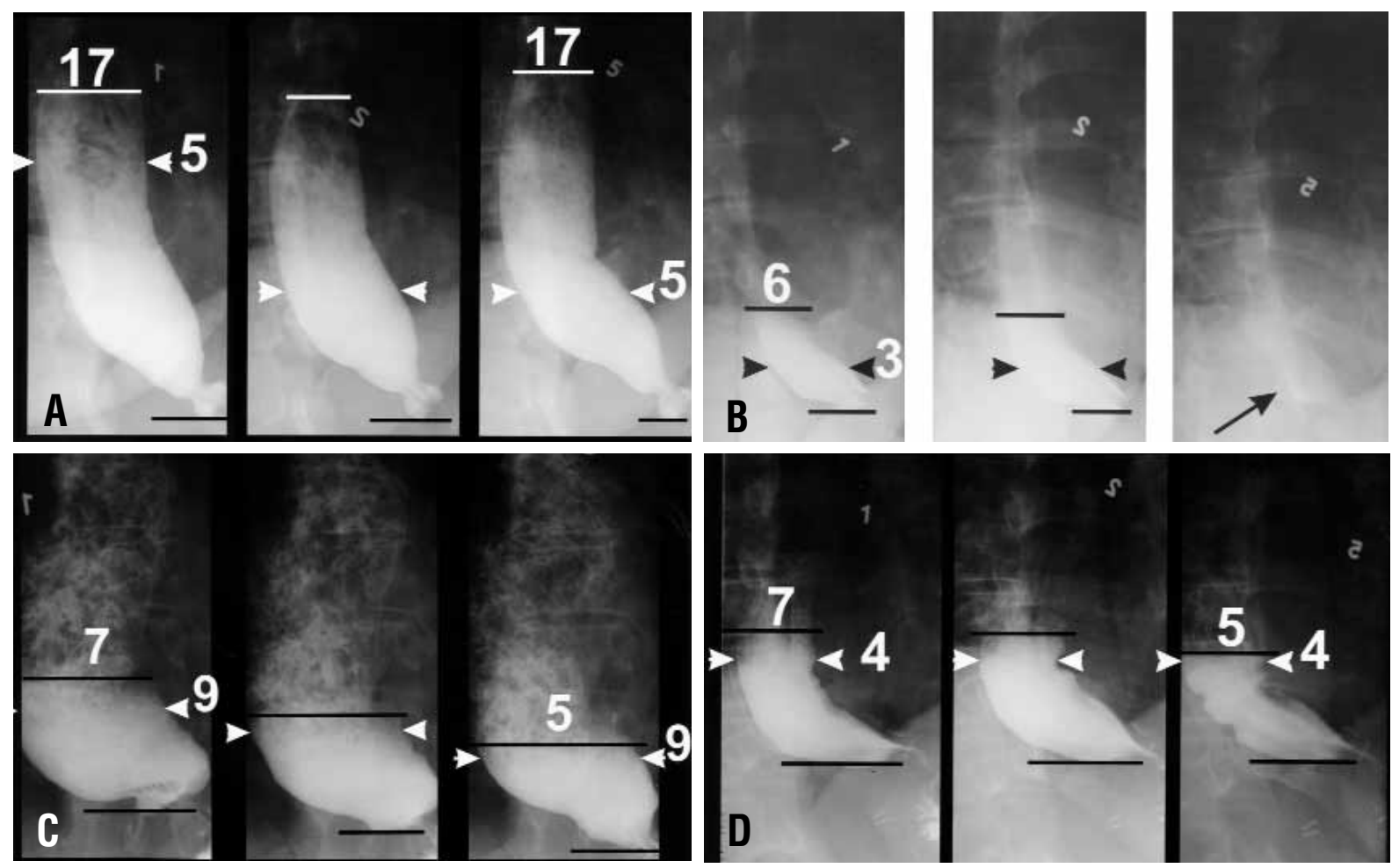

Fig 5. Relation of postmyotomy barium column height to premyotomy width in 2 patients. The depiction is as in Fig 1. A, Patient with moderately dilated esophagus without emptying by 5 minutes premyotomy. B, The same patient postmyotomy showing markedly improved esophageal emptying with a trace of barium at 5 minutes. C, Patient with marked esophageal dilation premyotomy. D, The same patient postmyotomy showing improved but incomplete emptying at 5 minutes.

number of premyotomy pneumatic dilations, the lower the barium column height at 1 and 2 minutes (Appendix Tables I and II). Patients with premyotomy pneumatic dilations had 1-minute barium column heights of $16 \pm 8.0 \mathrm{~cm}$ compared with $21 \pm 7.0 \mathrm{~cm}$ $(P=.03)$ in patients without dilations.

Barium column width. A person with normal esophageal function has a maximum esophageal width by barium esophagogram of 2 to $3 \mathrm{~cm}$ and has a collapsed esophagus at 1 minute. In contrast, these patients with achalasia had a median width of the barium column premyotomy of $5.2,4.8$, and $4.5 \mathrm{~cm}$ at 1,2 , and 5 minutes after barium ingestion (Fig 5). Postmyotomy, the median width of the barium column was $3.5,3.0$, and $1.0 \mathrm{~cm}$ at 1,2 , and 5 minutes after barium ingestion (Fig 6; $P<.001$ at each time).

The relation of premyotomy and postmyotomy barium column width at 1 minute for each patient is depicted in Fig 7. In contrast to the barium column height, there was a strong correlation between premyotomy and postmyotomy barium column widths: the larger the premyotomy width, the larger the postmyotomy width
( $r=0.55, P<.001, \mathrm{n}=42$ at 1 minute; $r=0.62, P<$ $.001, \mathrm{n}=41$ at 2 minutes; and $r=0.61, P<.001, \mathrm{n}=$ 42 at 5 minutes, Fig 8).

Demography, esophageal manometry, and prior therapy correlated weakly with premyotomy and postmyotomy barium column widths (Appendix Tables III and IV).

Symptom assessment. Postmyotomy, despite the observation that only $29 \%$ of the patients had complete esophageal emptying at 1 minute, $36 \%$ at 2 minutes, and $49 \%$ at 5 minutes, $95 \%$ experienced complete or near-complete relief of each symptom (grades $0-1$ ) (Table II) and 90\% experienced complete or near-complete relief of all symptoms. The patients experiencing at least frequent (grades 2-5) symptoms were different patients for each symptom. One patient each had only chest pain or heartburn. One patient had dysphagia and regurgitation. One additional patient had dysphagia, regurgitation, chest pain, and heartburn.

Symptoms and the TBE. Premyotomy symptoms correlated weakly $(-0.10<r<0.10)$ with barium column height, except for the severity of regurgitation, which worsened in proportion to the height of the bar- 


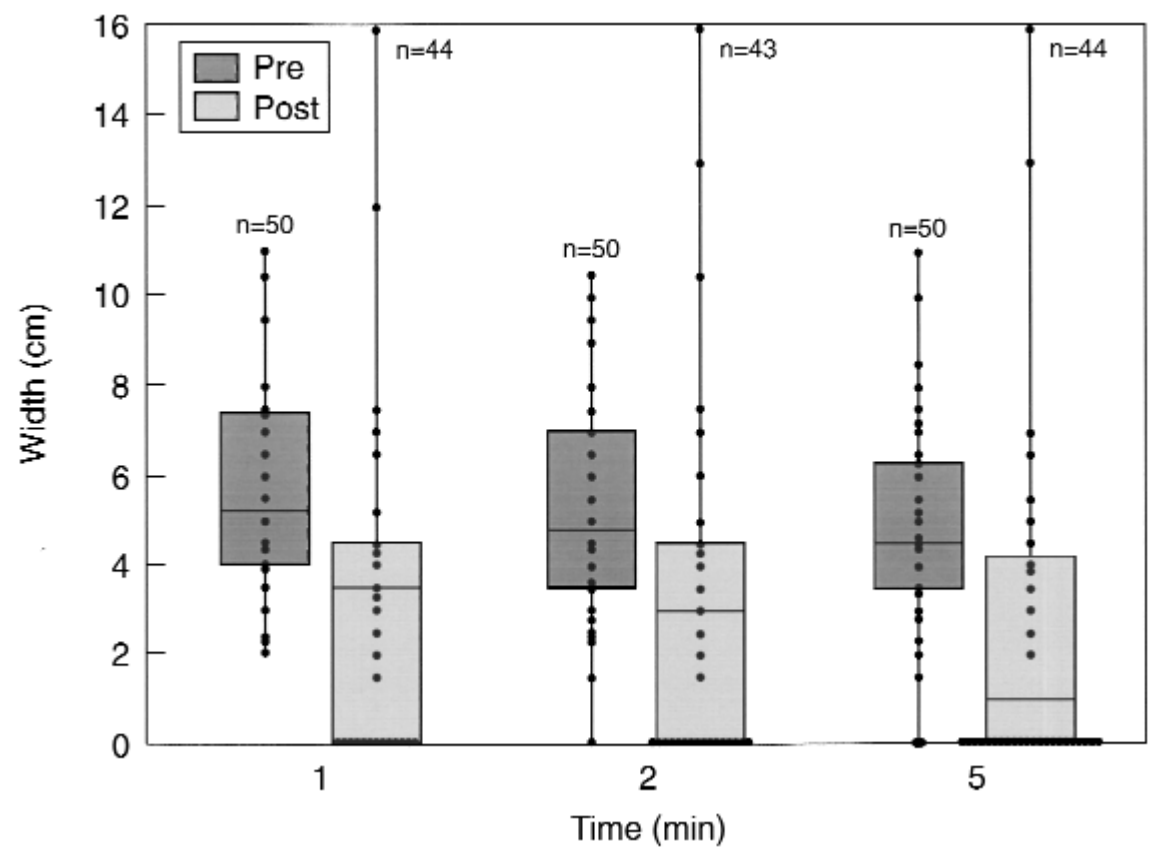

Fig 6. Premyotomy and postmyotomy barium column width at 1, 2, and 5 minutes. The depiction is as in Fig 2.

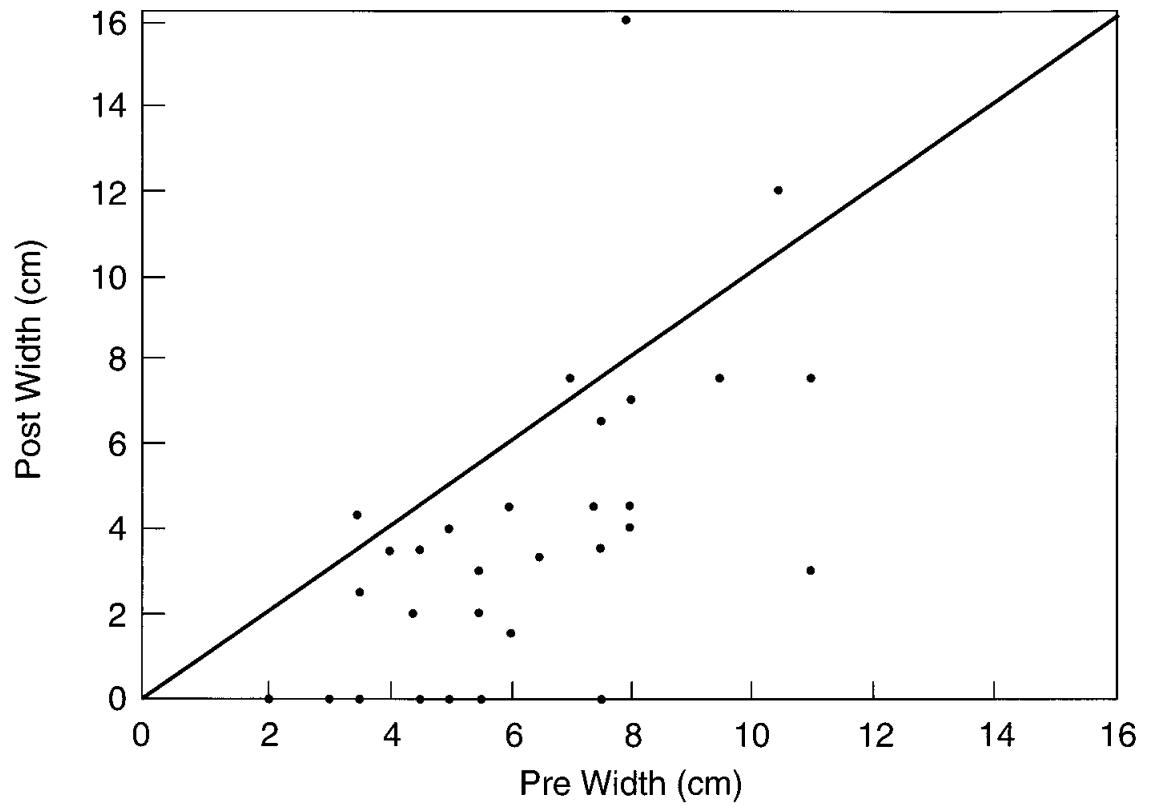

Fig 7. Relation of premyotomy barium column width at 1 minute to postmyotomy width at 1 minute. The line of identity is shown.

ium column $(r=0.45, P=.001$ at 1 minute; $r=0.38$, $P=.006$ at 2 minutes; and $r=0.40, P=.004$ at 5 minutes, Fig 9). Premyotomy symptoms correlated weakly $(-0.26<r<0.10)$ with barium column width, except for chest pain, which was weakly and inversely corre- lated with width $(r=-0.31, P=.03$ at 1 minute; $r=-0.34, P=.02$ at 2 minutes, and $r=-0.28, P=.04$ at 5 minutes). Premyotomy dysphagia was more severe when little change in width occurred from 1 to 5 minutes $(r=0.26, P=.07)$. 

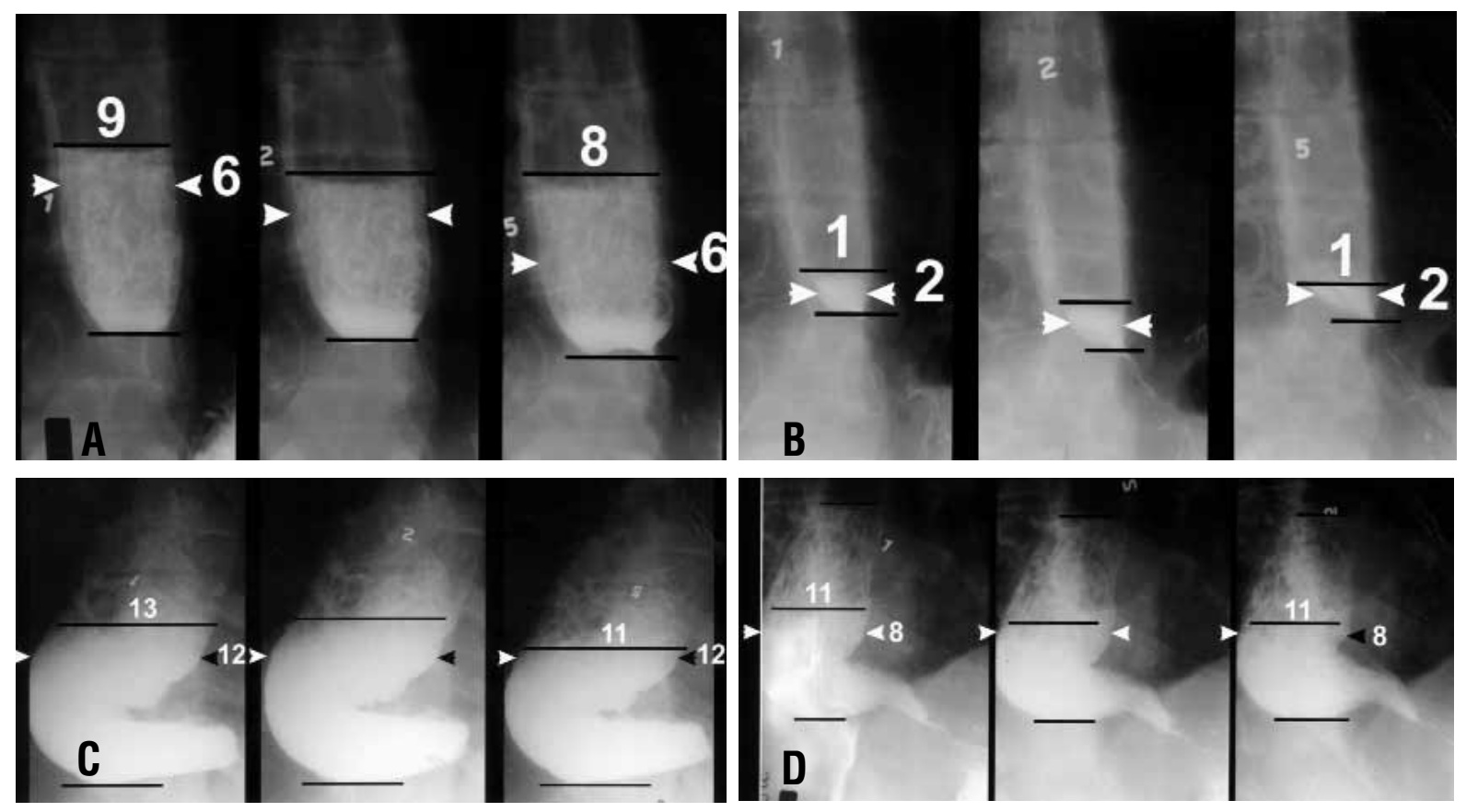

Fig 8. Relation of postmyotomy barium column width to premyotomy width in 2 patients. The depiction is as in Fig 5. A, Patient with moderately dilated esophagus with minimal emptying by 5 minutes premyotomy. B, The same patient postmyotomy showing near-complete emptying. C, Patient with a markedly dilated sigmoid esophagus showing minimal emptying by 5 minutes premyotomy. D, The same patient postmyotomy showing decreased barium column height and width, but with minimal emptying by 5 minutes.

Symptoms postmyotomy, which were rare, correlated poorly with residual barium column height and width.

\section{Discussion}

By the time symptoms of achalasia develop, the esophageal myenteric plexus has been irreparably damaged, if not totally replaced by fibrous tissue. Therefore, no therapy can restore normal esophageal function. The goal of palliative treatment is to convert the esophagus into a passive conduit and improve esophageal emptying by gravity. Because peristalsis does not return, it is unreasonable to expect normal esophageal emptying even with a successful myotomy. Assessment of the results of therapy for achalasia has been confusing because many patients and physicians expect restoration of normal esophageal emptying.

Previously, the only measure of esophageal emptying has been radionuclide studies. These are expensive, not widely available, provide poor anatomic detail, and are difficult to perform repeatedly. All other measurements indirectly assess esophageal emptying. These include manometry, simple barium esophagography, endoscopy, and imaging such as computed tomographic scanning.
The TBE is a simple test that directly measures liquid esophageal emptying. It is easy to do, requiring no special equipment or expertise. Therefore, TBE is repeatable and can be performed at institutions other than the one at which treatment was undertaken. It is also inexpensive, quantitative, and comfortable for the patient. These factors make it an ideal, practical test for serial assessments of esophageal emptying. Successful treatment by myotomy is reflected in improved emptying of the esophagus, resulting in both a decreased height and width of the esophagus.

The less the esophagus was dilated premyotomy, the greater the improvement in esophageal emptying. Both the height and width of the barium column postmyotomy were directly related to the premyotomy width. The neural destruction in achalasia results in an abnormal relaxation of the lower esophageal sphincter and aperistalsis of the esophageal body. Therapy is directed only at the lower esophageal sphincter and assumes that relief of obstruction will result in restoration of normal esophageal width. However, dilation of the esophagus also may reflect or result in decompensation of the esophageal body that may not be reversed by therapy. We interpret the correlation of TBE height and width 
Table II. Symptoms

\begin{tabular}{|c|c|c|c|c|c|}
\hline \multirow[b]{2}{*}{ Symptom } & \multicolumn{2}{|c|}{ Premyotomy $(n=46)$} & \multicolumn{2}{|c|}{ Postmyotomy $(n=42)$} & \multirow{2}{*}{$\begin{array}{c}\mathrm{P} \text { value* } \\
\text { (pre to post) }\end{array}$} \\
\hline & No. & $\%$ & No. & $\%$ & \\
\hline Dysphagia & & & & & $<.001$ \\
\hline None & 11 & 24 & 37 & 88 & \\
\hline Rare & 2 & 4 & 3 & 7 & \\
\hline Occasional & 5 & 11 & 0 & 0 & \\
\hline Frequent & 1 & 2 & 0 & 0 & \\
\hline Very often & 4 & 9 & 1 & 2 & \\
\hline Severe & 23 & 50 & 1 & 2 & \\
\hline Regurgitation & & & & & $<.001$ \\
\hline None & 5 & 11 & 37 & 88 & \\
\hline Rare & 5 & 11 & 3 & 7 & \\
\hline Occasional & 6 & 13 & 0 & 0 & \\
\hline Frequent & 11 & 24 & 0 & 0 & \\
\hline Very often & 4 & 9 & 1 & 2 & \\
\hline Severe & 15 & 33 & 1 & 2 & \\
\hline Chest pain & & & & & $<.001$ \\
\hline None & 23 & 50 & 37 & 88 & \\
\hline Rare & 7 & 15 & 3 & 7 & \\
\hline Occasional & 7 & 15 & 0 & 0 & \\
\hline Frequent & 4 & 9 & 0 & 0 & \\
\hline Very often & 0 & 0 & 1 & 2 & \\
\hline Severe & 5 & 11 & 1 & 2 & \\
\hline Heartburn & & & & & $<.001$ \\
\hline None & 15 & 33 & 36 & 86 & \\
\hline Rare & 8 & 17 & 4 & 10 & \\
\hline Occasional & 8 & 17 & 0 & 0 & \\
\hline Frequent & 5 & 11 & 1 & 2 & \\
\hline Very often & 2 & 4 & 0 & 0 & \\
\hline Severe & 8 & 17 & 1 & 2 & \\
\hline
\end{tabular}

*P value reflects 42 pairs of data.

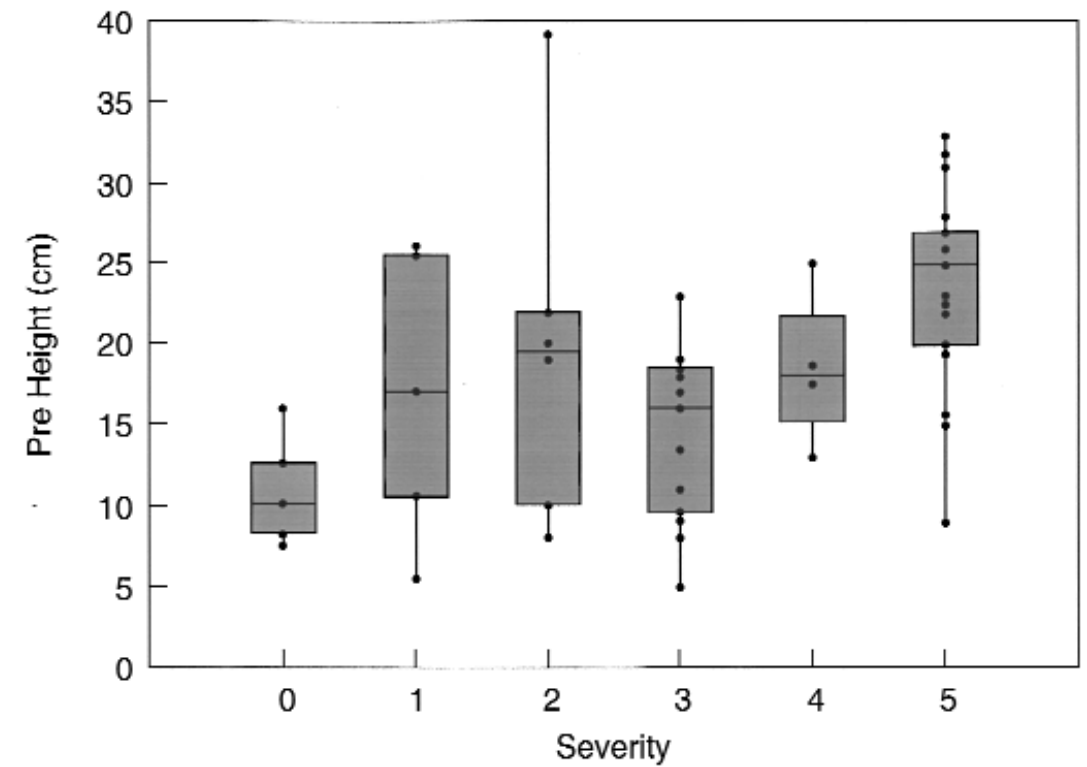

Fig 9. Relation of premyotomy barium column height to severity of regurgitation. The depiction is similar to that in Fig 2. 
postmyotomy as reflecting the degree of irreversible decompensation, whereas the lack of correlation premyotomy reflects the dominance of lower esophageal obstruction. So that esophageal emptying can be facilitated and the denervated esophagus maximally palliated, early and effective treatment should be undertaken to prevent dilation of the esophagus.

Because of its simplicity, symptom relief traditionally is used to assess the outcome of achalasia therapy. However, disparity between symptomatic response and objective improvement in achalasia has been noted. ${ }^{10-14}$ There are three probable explanations for this dissociation. First, swallowing is so difficult for patients with achalasia that any improvement is often exaggerated. Second, eating is such a great part of our social lives that any improvement is greatly appreciated. ${ }^{15}$ Third, denervation of the esophagus alters perception of swallowing. ${ }^{5}$ Consequently, it is difficult to determine the success of therapy by symptom evaluation alone.

The association of premyotomy symptoms to TBE has interesting physiologic and pathologic correlations. In the process of esophageal denervation with incomplete lower esophageal sphincter relaxation, the height of the barium column increases because of incomplete emptying. As the obstruction persists, the esophagus decompensates over time by dilating, as in the failing myocardium. Physiologically, regurgitation is likely to be the principal symptom if a large volume of barium is close to the pharynx, as measured by barium column height. Similarly, the symptom of dysphagia is worse if there is less emptying of the esophagus, as reflected by a lack of change in width from 1 to 5 minutes. Early in the destructive process, when the esophagus is not very dilated, the partially denervated esophagus is more likely to undergo lumen-occluding spasm (vigorous achalasia), causing the patient to have chest pain. Patients with significant chest pain may be the best candidates for aggressive surgical management since they are likely to have a less dilated esophagus.

Symptoms postmyotomy are unrelated to esophageal emptying and are poor measures of success of therapy. Therefore, TBE should be included in the preoperative evaluation and postoperative follow-up of all patients undergoing therapy for achalasia. It defines the physiologic success of surgery, prevents unnecessary opera- tion when symptoms persist or recur, and prompts further study and possible therapy in the asymptomatic patient with unimproved esophageal emptying.

\section{REFERENCES}

1. Goldblum JR, Whyte RI, Orringer MB, Appleman HD. Achalasia: a morphologic study of 42 resected specimens. Am J Surg Pathol 1994;18:327-37.

2. Goldblum JR, Rice TW, Richter JE. Histopathologic features in esophagomyotomy specimens from patients with achalasia. Gastroenterology 1996;111:648-54.

3. Clark SB, Rice TW, Tubbs RR, Richter JE, Goldblum JR. The nature of the myenteric infiltrate in achalasia. Am J Surg Pathol 2000;24:1153-8

4. Birgisson S, Galinski MS, Goldblum JR, Rice TW, Richter JE. Achalasia is not associated with measles or known herpes and human papilloma viruses. Dig Dis Sci 1997;42:300-6.

5. Paterson WG. Esophageal and lower sphincter response to balloon distention in patients with achalasia. Dig Dis Sci 1997;42:106-12.

6. Torbey CF, Achkar E, Rice TW, Baker ME, Richter JE. Longterm outcome of achalasia treatment: the need for closer followup. J Clin Gastroenterol 1999;28:125-36.

7. de Oliveira JMA, Birgisson S, Doinoff C, Einstein D, Herts B, Davros W, et al. Timed barium swallow: a simple technique for evaluating esophageal emptying in patients with achalasia. Am J Radiol 1997;169:473-9.

8. Vaezi MF, Baker ME, Richter JE. Assessment of esophageal emptying post-pneumatic dilation: use of the timed barium esophagram. Am J Gastroenterol 1999;94:1802-7.

9. Neter J, Kutner MH, Nachtsheim CJ, Wasserman W. Building the regression model II: diagnostics. Chapter 9. In: Applied linear statistical models. Chicago: Irwin; 1996. p. 361-99.

10. Holloway RH, Krosin G, Lange RC, Baue AE, McCallum RW. Radionuclide esophageal emptying of a solid meal to quantitate results of therapy in achalasia. Gastroenterology 1983;84:771-6.

11. Robertson CS, Hardy JG, Atkinson M. Quantitative assessment of the response to therapy in achalasia of the cardia. Gut 1989;30:768-73

12. Vantrappen G, Hellemans J, Deloof W, Valembois P, Vandenbroucke J. Treatment of achalasia with pneumatic dilatations. Gut 1971;12:268-75.

13. Vaezi MF, Richter JE, Wilcox CM, Schroeder PL, Birgisson S, Slaughter RL, et al. Botulinum toxin versus pneumatic dilatation in the treatment of achalasia: a randomised trial. Gut 1999;44:231-9.

14. Eckardt VF, Aignherr C, Bernhard G. Predictors of outcome in patients with achalasia treated by pneumatic dilation. Gastroenterology 1992;103:1732-8.

15. DeMeester TR. Invited commentary in Banbury MK, Rice TW, Goldblum JR, Clark SB, Baker ME, Richter JE, et al. Esophagectomy with gastric reconstruction for achalasia. J Thorac Cardiovasc Surg 1999;117:1077-85. 
Appendix Table I. Univariable correlates of barium column height premyotomy

\begin{tabular}{|c|c|c|c|c|c|c|c|}
\hline \multirow[b]{2}{*}{ Variable } & \multirow[b]{2}{*}{$n$} & \multicolumn{2}{|c|}{ One minute } & \multicolumn{2}{|c|}{ Two minutes } & \multicolumn{2}{|c|}{ Five minutes } \\
\hline & & $\begin{array}{l}\text { Mean } \pm S D \\
\text { (correlation) }\end{array}$ & $\mathrm{P}$ & $\begin{array}{l}\text { Mean } \pm S D \\
\text { (correlation) }\end{array}$ & $\mathrm{P}$ & $\begin{array}{l}\text { Mean } \pm S D \\
\text { (correlation) }\end{array}$ & $\mathrm{P}$ \\
\hline \multicolumn{8}{|l|}{ Demography } \\
\hline Sex & & & .8 & & .9 & & 6 \\
\hline Male & 25 & $19 \pm 7.2$ & & $17 \pm 7.5$ & & $16 \pm 7.7$ & \\
\hline Female & 25 & $18 \pm 8.7$ & & $17 \pm 8.4$ & & $14 \pm 7.5$ & \\
\hline Age (y) & 50 & 0.014 & .9 & 0.040 & .8 & 0.003 & .99 \\
\hline Weight $(\mathrm{kg})$ & 50 & 0.009 & .95 & -0.007 & .96 & -0.016 & .9 \\
\hline \multicolumn{8}{|l|}{ Esophageal manometry } \\
\hline LES pressure (mean, mm Hg) & 46 & 0.22 & .13 & 0.23 & .12 & 0.10 & .5 \\
\hline Body amplitude (mean, mm Hg) & 42 & 0.16 & .3 & 0.15 & .3 & 0.088 & .6 \\
\hline \multicolumn{8}{|l|}{ Previous therapies } \\
\hline Botox injections (No.) & 50 & 0.014 & .9 & 0.008 & .95 & -0.001 & .99 \\
\hline Pneumatic dilations (No.) & 50 & -0.26 & .06 & -0.26 & .07 & -0.17 & .2 \\
\hline Previous operations & & & .2 & & .4 & & .3 \\
\hline No & 46 & $19 \pm 7.8$ & & $17 \pm 7.9$ & & $15 \pm 7.5$ & \\
\hline Yes & 4 & $14 \pm 8.2$ & & $14 \pm 9.2$ & & $12 \pm 7.7$ & \\
\hline
\end{tabular}

$S D$, Standard deviation; LES, lower esophageal sphincter.

Appendix Table II. Univariable correlates of barium column height postmyotomy

\begin{tabular}{|c|c|c|c|c|c|c|c|}
\hline \multirow[b]{2}{*}{ Variable } & \multirow[b]{2}{*}{$n$} & \multicolumn{2}{|c|}{ One minute } & \multicolumn{2}{|c|}{ Two minutes } & \multicolumn{2}{|c|}{ Five minutes } \\
\hline & & $\begin{array}{l}\text { Median }(I Q) \\
\text { (correlation) }\end{array}$ & $\mathrm{P}$ & $\begin{array}{c}\text { Median }(I Q) \\
\text { (correlation) }\end{array}$ & $\mathrm{P}$ & $\begin{array}{c}\text { Median }(I Q) \\
\text { (correlation) }\end{array}$ & $\mathrm{P}$ \\
\hline \multicolumn{8}{|l|}{ Demography } \\
\hline \multicolumn{8}{|l|}{ Sex } \\
\hline Male & 24 & $4.75(0-13)$ & .8 & $2(0-11.5)$ & .8 & $0(0-5.75)$ & .95 \\
\hline Female & 21 & $7(1.5-9)$ & & $6.5(1.5-9)$ & & $4(0-8.5)$ & \\
\hline Age (y) & 45 & 0.055 & .7 & -0.003 & .9 & -0.002 & .99 \\
\hline Weight $(\mathrm{kg})$ & 45 & 0.099 & .5 & 0.15 & .4 & 0.21 & .16 \\
\hline \multicolumn{8}{|l|}{ Esophageal manometry } \\
\hline LES pressure (mean, mm Hg) & 41 & -0.098 & .5 & -0.010 & .95 & -0.035 & .8 \\
\hline Body amplitude (mean, $\mathrm{mm} \mathrm{Hg}$ ) & 38 & -0.072 & .7 & -0.035 & .8 & -0.11 & .5 \\
\hline \multicolumn{8}{|l|}{ Previous therapies } \\
\hline Botox injections (No.) & 45 & 0.095 & .5 & -0.024 & .9 & -0.080 & 6 \\
\hline Pneumatic dilations (No.) & 45 & -0.097 & .5 & -0.027 & .9 & 0.036 & .8 \\
\hline \multicolumn{8}{|l|}{ Previous operations } \\
\hline No & 42 & $7(0-13)$ & 6 & $5(0-11.5)$ & .8 & $0(0-6)$ & .9 \\
\hline Yes & 3 & $5.5(1.5-8.5)$ & & $5.5(1.5-8.5)$ & & $5.5(1-8.5)$ & \\
\hline
\end{tabular}

$I Q$, Interquartile values; $L E S$, lower esophageal sphincter.

\section{Discussion}

Dr Thomas R. J. Todd (Abu Dhabi, United Arab Emirates). The essential thesis of this paper is that the esophagogram evaluates the effectiveness of the myotomy for achalasia better than does an evaluation of the symptoms themselves. The authors have demonstrated unequivocally that there is no association between the improvement in the esophagogram and the resolution of the symptoms. This was also shown to be the case after balloon dilatation in a study from their own center that appeared last July in Gastroenterology. What has not been shown, to my knowledge, is whether the esophagogram possesses sufficient sensitivity to permit one to conclude that a certain level of improvement in emptying radiographically correlates with a sufficient reduction in lower esophageal sphincter pressure to permit symptoms to disappear. In other words, an improvement in the barium esophagogram may not indicate that the myotomy has been sufficiently complete to ensure that no 
Appendix Table III. Univariable correlates of barium column width before myotomy

\begin{tabular}{|c|c|c|c|c|c|c|c|}
\hline \multirow[b]{2}{*}{ Variable } & \multirow[b]{2}{*}{$n$} & \multicolumn{2}{|l|}{ One minute } & \multicolumn{2}{|c|}{ Two minutes } & \multicolumn{2}{|c|}{ Five minutes } \\
\hline & & $\begin{array}{l}\text { Mean } \pm S D \\
\text { (correlation) }\end{array}$ & $\mathrm{P}$ & $\begin{array}{l}\text { Mean } \pm S D \\
\text { (correlation) }\end{array}$ & $\mathrm{P}$ & $\begin{array}{l}\text { Mean } \pm S D \\
\text { (correlation) }\end{array}$ & $\mathrm{P}$ \\
\hline \multicolumn{8}{|l|}{ Demography } \\
\hline Sex & & & .5 & & .6 & & .5 \\
\hline Male & 25 & $5.7 \pm 2.3$ & & $5.5 \pm 2.6$ & & $5.2 \pm 2.6$ & \\
\hline Female & 25 & $5.3 \pm 2.2$ & & $5.1 \pm 2.3$ & & $4.8 \pm 2.4$ & \\
\hline Age (y) & 50 & 0.070 & 6 & 0.101 & .5 & 0.035 & .8 \\
\hline Weight $(\mathrm{kg})$ & 50 & -0.041 & .8 & -0.063 & .7 & -0.056 & .7 \\
\hline \multicolumn{8}{|l|}{ Esophageal manometry } \\
\hline LES pressure (mean, mm Hg) & 46 & 0.25 & .1 & 0.26 & .08 & 0.25 & .09 \\
\hline Body amplitude (mean, $\mathrm{mm} \mathrm{Hg}$ ) & 42 & -0.21 & .18 & -0.21 & .19 & -0.29 & .07 \\
\hline \multicolumn{8}{|l|}{ Previous therapies } \\
\hline Botox injections (No.) & 50 & -0.17 & .2 & -0.13 & .4 & -0.16 & .3 \\
\hline Pneumatic dilations (No.) & 50 & 0.002 & .99 & 0.066 & 6 & 0.063 & .7 \\
\hline Previous operations & & & .98 & & .5 & & .5 \\
\hline No & 46 & $5.5 \pm 2.2$ & & $5.2 \pm 2.3$ & & $4.9 \pm 2.5$ & \\
\hline Yes & 4 & $5.6 \pm 2.9$ & & $6.1 \pm 3.4$ & & $5.8 \pm 3.2$ & \\
\hline
\end{tabular}

$S D$, Standard deviation; LES, lower esophageal sphincter.

Appendix Table IV. Univariable correlates of barium column width postmyotomy

\begin{tabular}{|c|c|c|c|c|c|c|c|}
\hline \multirow[b]{2}{*}{ Variable } & \multirow[b]{2}{*}{$n$} & \multicolumn{2}{|c|}{ One minute } & \multicolumn{2}{|c|}{ Two minutes } & \multicolumn{2}{|c|}{ Five minutes } \\
\hline & & $\begin{array}{l}\text { Median }(I Q) \\
\text { (correlation) }\end{array}$ & $\mathrm{P}$ & $\begin{array}{c}\text { Median }(I Q) \\
\text { (correlation) }\end{array}$ & $\mathrm{P}$ & $\begin{array}{l}\text { Median }(I Q) \\
\text { (correlation) }\end{array}$ & $\mathrm{P}$ \\
\hline \multicolumn{8}{|l|}{ Demography } \\
\hline \multicolumn{8}{|l|}{ Sex } \\
\hline Male & 24 & $3.4(0-4.5)$ & .5 & $2(0-5)$ & 6 & $0(0-4.25)$ & .7 \\
\hline Female & 20 & $3.5(1-4.4)$ & & $3.25(0.75-4.15$ & & $2.75(0-4)$ & \\
\hline Age (y) & 44 & 0.190 & .2 & 0.145 & .4 & 0.131 & .4 \\
\hline Weight $(\mathrm{kg})$ & 44 & 0.072 & .6 & 0.13 & .4 & 0.13 & .4 \\
\hline \multicolumn{8}{|l|}{ Esophageal manometry } \\
\hline LES (mean, mm Hg) & 40 & -0.066 & .7 & -0.042 & .8 & -0.043 & .8 \\
\hline Body amplitude (mean, $\mathrm{mm} \mathrm{Hg}$ ) & 37 & -0.19 & .3 & -0.17 & .3 & -0.17 & .3 \\
\hline \multicolumn{8}{|l|}{ Previous therapies } \\
\hline Botox injections (No.) & 44 & 0.091 & .6 & -0.029 & .8 & 0.001 & .99 \\
\hline Pneumatic dilations (No.) & 44 & 0.49 & $<.001^{*}$ & 0.52 & $<.001^{*}$ & 0.50 & $<.001 *$ \\
\hline Previous operations & & & .4 & & .3 & & .3 \\
\hline No & 41 & $3.3(0-4.5)$ & & $2.75(0-4.4)$ & & $0(0-4)$ & \\
\hline Yes & 3 & $4(3.5-16)$ & & $4(3.5-16)$ & & $3.5(3.5-16)$ & \\
\hline
\end{tabular}

$I Q$, Interquartile values.

*Correlation found to be due solely to the patient with the most dilations having the highest postmyotomy values.

residual symptoms are present in a patient with an aperistaltic esophagus.

Given this apparent lack of correlation between residual symptoms and the improvement in esophageal emptying by TBE, the authors state that the TBE is thus useful in establishing that emptying has improved in patients with persisting symptoms and thus in preventing subsequent unnecessary surgery.
The essential question, though, is this: What is the cause of the persisting symptoms and which study best delineates that cause? About a year ago, Alonso and associates reported that manometric examination accurately records whether a satisfactory myotomy has been performed, and I concur with that.

Patients with residual symptoms after myotomy fall into several possible categories. First, they have had an adequate myotomy, but symptoms persist because of the denervation. 
Second, they have had an inadequate myotomy despite an improvement in emptying because the esophagus is aperistaltic. Alonso and associates, in their article, did define the levels of postoperative pressure manometrically that would result in persistent symptoms. The third possibility is that the patient now has reflux and all the problems of reflux. In all of these possibilities, the esophagogram would show improvement, but manometry might differentiate these possibilities. Thus, I believe that the esophagogram is a useful adjunct in the assessment of these patients, but I question whether it can replace manometry in accurate assessment of ongoing pathophysiology.

I have 2 questions: First, did you perform manometry and $\mathrm{pH}$ studies postoperatively in the patients with residual symptoms so that you could then compare these results with the esophagogram? Second, particularly as I know you use esophagography after balloon dilatation, do you have any longitudinal data of esophagography to indicate whether it subsequently changes when recurrent symptoms develop after an initial improvement?

Dr Steve R. DeMeester (Los Angeles, Calif). Did you identify a cutoff point at which the esophagus was so dilated that you could predict with reliability that it was not going to empty well postoperatively? Along those same lines, did you try a myotomy on patients whose esophagus had a sigmoid shape, and who generally are not considered to be good candidates for myotomy? What type of fundoplication did you use, and was there a difference between a Toupet or a Dor procedure? Last, did you compare surgical myotomy and balloon dilatation in terms of timed emptying?

Dr Antoon E. M. R. Lerut (Leuven, Belgium). The timing of this study, 8 weeks after the operation, seems too early since postoperative edema and all the related changes have not resolved. Did you perform some studies later, at 4 or 6 months, for instance, and was there any difference compared with the results at 8 weeks?

Dr DeCamp. I would like to thank the discussants for their insightful questions.

To address Dr Todd, 95\% of patients had effective relief of symptoms, so it was a vast minority of patients who had residual symptoms. Those patients whose symptoms were severe enough to make them consider having another intervention, namely, either balloon dilatation, which we have done on a rare occasion, or a reoperation, underwent exten- sive re-evaluation, including a $\mathrm{pH}$ study and repeat manometry. These studies were designed to discriminate between reflux disease and a stricture (of which we think we have 2 fairly well-documented cases) or an incomplete myotomy.

The issue of residual lower esophageal sphincter pressure is a bit of a moving target. What I did not discuss is the fundoplication associated with myotomy. Our experience is certainly an evolving one. Initially the patients rather routinely had a Toupet procedure. We did not use Dor procedures, preferring the more minimal dissection of the hiatal mechanism and not using any fundoplication in our most recent series. Forty-seven of the 52 patients whom we discussed had their procedure performed laparoscopically. So, to address Dr Lerut, I think 8 weeks is probably sufficient for resolution of postoperative edema from a laparoscopic procedure.

Regarding the question by Dr Todd, in terms of longterm follow-up, it is our practice to recommend careful follow-up of those patients who have incomplete emptying, those whom we think are at risk for the development of sigmoid deformity. This paper is considering just a surgical series. When we look at all patients, we are evaluating both the medical and surgical management. We think this tool is also useful for patients in the balloon dilatation group. The patient whose condition is symptomatically improved by balloon dilatation but who by esophagogram has residual dilatation should be observed carefully and closely, and surgical intervention should be recommended before a sigmoid deformity develops.

Dr DeMeester asked whether we have a cutoff above which we would predict poor emptying. At $6 \mathrm{~cm}$ or less, we expect good outcomes symptomatically. On esophagogram, above $6 \mathrm{~cm}$ we continue to expect good symptomatic relief but also expect residual barium column height and width. We do offer almost all patients, other than those with the most grotesque sigmoid deformities, an attempt at a reparative procedure because the symptomatic improvement is so great and because a certain subset of these patients will be elderly and not particularly good candidates for esophageal resection. In addressing fundoplication, I observed that our experience is evolving. We believe that the Toupet procedure is a slightly better approach, which allows us to tack our myotomy open, whereas the Dor procedure tends to cover up what we have done. 